\title{
IMPROVED INTERFACIAL BONDING OF PVC/WOOD-FLOUR COMPOSITES BY LIGNIN AMINE MODIFICATION
}

\author{
Xiaopeng Yue, Fangeng Chen,* and Xuesong Zhou \\ Soda lignin was divided into two fractions with different molecular \\ weights by methanol extraction. Lignin amine was synthesized from the \\ low-molecular-weight lignin fraction via Mannich reaction and was used \\ for interfacial modification of poly-(vinylchloride) (PVC)/wood-flour \\ composites. The PVC/wood-flour composites were prepared from \\ surface-treated wood flour and PVC by melt compounding. The lignin \\ amine treatment provided almost equivalent improvement in mechanical \\ performances of composites as aminosilane treatment does. The tensile \\ and impact strengths of composites prepared from 30phr of wood flour \\ treated with $2 \mathrm{wt} \%$ lignin amine were increased by $21.0 \%$ and $43.9 \%$, \\ respectively, compared to those prepared from untreated wood flour. \\ Furthermore, lignin amine treatment could also significantly reduce the \\ water absorption of composites. A significant increase in storage \\ modulus ( $E$ ') was observed upon incorporation of wood flour with lignin \\ amine treatment. The improved dispersion of wood flour in polymer \\ matrix was observed by SEM images when the wood flour was treated \\ by lignin amine. The experimental data indicate that the polymer-wood \\ interfacial combination is strengthened.
}

Keywords: Polymer composites; Lignin amine; Wood flour; Poly-(vinyl chloride); Interfacial bonding

Contact information: State Key Laboratory of Pulp and Paper Engineering, South China University of Technology, Guangzhou 510640, China. *Corresponding author. Tel: +8620-87113940; fax: +862087113940; E-mail address: fgchen@scut.edu.cn

\section{INTRODUCTION}

The combination of wood and plastics offers potential for the provision of highvalue wood-plastic composites (WPC). WPC represents an emerging class of materials that combine the favorable performance and cost attributes of both wood and thermoplastics (Jiang and Kamdem 2004). Compared to wood, WPC has a longer service life with less need for maintenance, less water absorption, better dimensional stability, and less biodeterioration. The uses of WPC are increasing in construction, transportation, industrial, and consumer industries. General thermoplastics, e.g., polyethylene (PE), polypropylene (PP), poly (vinyl chloride) (PVC), and polystyrene (PS), are most commonly used as the polymer matrix in WPC (Bengtsson and Oksman 2006; Ichazo et al. 2001; Georgopoulos et al. 2005; Garcia-Hernandez et al. 2004).

Compatibility has been widely acknowledged to be one of the toughest problems in WPC due to the poor interfacial adhesion between polymers and wood ( $\mathrm{Lu}$ et al. 2000). Coupling agents or compatibilizers are commonly used to improve the interfacial adhesion between wood flour and a polymer matrix and, if possible, to solve this problem. For instance, aminosilane (Matuana et al. 1998a,b) and poly-[methyl 
(polyphenyl isocyanate)] (Bledzki et al. 1998) have been used in PVC/wood-flour composites to solve this problem. Therefore, natural polymers containing amino groups and hydroxyl groups within their molecules, such as chitin and chitosan, can also be used as coupling agents for PVC/wood-flour composites (Shah et al. 2005).

Lignin is the most abundant biopolymer second only to cellulose. Lignin isolated from the pulping process of wood or non-wood fibers has been used to prepare polyurethane, phenolic resins, epoxy resins, and other polymer materials (Kelley et al. 1990; Cetin and Ozmen 2002; Sun et al. 2007). Chemical modification is sometimes necessary to improve the performance of lignin-based products or to extend the utilization of lignin. Amination is one of the most important techniques. Lignin amine is widely used as an important additive, such as asphalt emulsifier (Lin 1985), flocculant (Hoftiezer et al. 1984), and dye dispersant (Dilling and Samaranayake 1999).

It is widely accepted that aminosilane can alter the acid-base interactions at the interface between wood flour and PVC matrix due to the existence of amino groups (Matuana et al. 1998a,b). Similar functional groups, i.e., amino groups and hydroxyls, are present in the molecules of lignin amine, aminosilane, and chitosan. Therefore, lignin amine can also improve the interfacial bonding between wood and PVC. However, the utilization of lignin amine in WPC has been seldom reported. In the present work, lignin amine was synthesized from lignin, formaldehyde, and diethylenetriamine (DETA) via Mannich reaction and was used as an interfacial modifier in PVC/wood-flour composites. PVC/wood-flour composites were prepared from treated wood flour and PVC by melt compounding. The tensile and impact strengths, water absorption and morphologies of composites were investigated. Furthermore, the coupling effects of lignin amine and aminosilane on PVC/wood composite were also compared.

\section{EXPERIMENTAL}

\section{Materials}

Softwood soda lignin (SL) was supplied by Tiger Forest and Paper Group Co., Ltd, Hunan Province, China. PVC with trade name DG-1000, was purchased from Dagu Chemical Co. Ltd, Tianjin, China. Wood flour from poplar with an average size of 100 mesh was supplied by Jinye Wood Fibers Factory, Hebei Province, China. The thermal stabilizer, sold with the trade name Baerostab, was the commercial products of Baerlother Co., Ltd, Malaysia. Monostearin, used as the lubricant, was the commercial product of Masson Chemical Co. Ltd, Guangzhou, China. Chlorinated polyethylene (CPE), used as the impact modifier, was the commercial product of Huaxing Additives Co. Ltd, Shandong Province, China. Triethoxy-3-aminopropylsilane (aminosilane), sold with the trade name KH-550, was the commerical product of Juchengzhaoye Silicone Co. Ltd, Guangzhou, China. Diethylenetriamine (DETA), formaldehyde and other chemicals were of reagent grade and used as received.

\section{Fractionation of Soda Lignin}

SL was extracted with methanol until the solution became colorless. The lignin solution that was concentrated by rotary evaporator was added into an excess of water to 
precipitate. The precipitated lignin fraction was named LA. The insoluble lignin fraction was named LB. The fractions were vacuum-dried and ground.

\section{Amination of Lignin}

$10 \mathrm{~g}$ of LA and $6.0 \mathrm{~g}$ of DETA were dissolved in $100 \mathrm{~mL} 0.5 \mathrm{~mol} / \mathrm{L} \mathrm{NaOH}$ solution. The $\mathrm{pH}$ of solution was adjusted to 11.5 using hydrochloric acid solution. The solution was added into a three-necked flask. Then $6.0 \mathrm{~g}$ of formaldehyde solution (37wt\%) was added step-wise with stirring. The reaction was carried out at $75{ }^{\circ} \mathrm{C}$ for $3 \mathrm{~h}$. After that, the solution was added into about 3 times its volume of i-propanol to precipitate lignin amine. The lignin amine was recovered by filtration, and washed by ipropanol several times, then vacuum-dried and ground.

\section{Surface Treatment of Wood Flour and Composite Manufacture}

A solution of $10 \mathrm{wt} \%$ lignin amine in methanol and a solution of $10 \mathrm{wt} \%$ aminosilane in ethanol/water mixture $(4: 1 \mathrm{v}: \mathrm{v})$ were prepared. Then, the solution of lignin amine or aminosilane was sprayed on wood flour. The wood flour was stirred at 2500 rpm until all the coating was applied. The loading of the lignin amine or aminosilane on the wood flour was $1 \%$ to $5 \%$. The coated wood flour was placed in an oven at $105^{\circ} \mathrm{C}$ for approximately $12 \mathrm{~h}$ to remove the solvent up to constant weight.

Table 1. Typical Formula of PVC/Wood-Flour Composites

\begin{tabular}{cccccc}
\hline Ingredients & PVC & Wood flour & $\begin{array}{c}\text { Impact } \\
\text { modifier }\end{array}$ & $\begin{array}{c}\text { Thermal } \\
\text { stabilizer }\end{array}$ & Lubricant \\
\hline Loading (g) & 100 & $30 \sim 50$ & 8 & 4 & 2 \\
\hline
\end{tabular}

The PVC/wood-flour composites were prepared according to the formula listed in Table 1 by melt compounding. The mixture was processed with an open-roll mixer at approximately $175^{\circ} \mathrm{C}$ for $5 \mathrm{~min}$. The sheets of approximately $2 \mathrm{~mm}$ and $4 \mathrm{~mm}$ thickness were compress-molded at $190{ }^{\circ} \mathrm{C}$ for $5 \mathrm{~min}$, and then air-cooled for $15 \mathrm{~min}$ under constant pressure before removal from the mold. The composites prepared from untreated wood flour, wood flour treated by lignin amine, and aminosilane were named PVC-UWF, PVC-LWF, and PVC-KWF, respectively.

\section{Characterization of Lignin, Lignin Amine and Composites}

The content of phenolic hydroxyl of lignin was determined by non-aqueous conductometric titration (El-Mansouri and Salvadó 2007).

The average molecular weight and the molecular weight distribution of lignin were estimated by GPC on an Agilent-1100 apparatus equipped with an Agilent-25 column and a R401 differential refractory detector. THF was used as the eluent. A series of narrow-dispersed polystyrene standard samples were used to calibrate the column.

The FT-IR spectra were obtained on a Nicolet Nexus 670 Fourier transform infrared spectrometer using $\mathrm{KBr}$ pellet technique. The samples were scanned 32 times with a wavenumber range of 4000 to $400 \mathrm{~cm}^{-1}$.

The elemental analysis of lignin and lignin amine were preformed in an Elementar Vario EL instrument. 
The sheets were cut to shoulder-shaped specimens and un-notched impact specimens. The tensile strength of PVC/wood composites were tested according to ISO 527:1996 with an INSTRON 5565 universal testing machine at a crosshead speed of 10 $\mathrm{mm} / \mathrm{min}$. The impact strength was tested according to ISO 8256:2004 with an INSTRON POE 2000 impact testing machine. At least quintuplet specimens were tested.

The water absorption was measured according to ISO 62-2008. The water uptake between samples was compared by weight percent change. The sample size was $80 \mathrm{~mm}$ $\times 10 \mathrm{~mm} \times 4 \mathrm{~mm}$. All samples were immersed in distilled water for the desired time. Before testing, the samples were allowed to drip dry for $10 \mathrm{~min}$, and any excess surface water was wiped off with a paper towel.

Dynamic mechanical analysis (DMA) was carried out with a Netzsch 242c instrument. The samples with dimensions of $40 \mathrm{~mm} \times 5 \mathrm{~mm} \times 2 \mathrm{~mm}$ were used in the three-point bending mode. DMA scans were recorded at an oscillation frequency of $1 \mathrm{~Hz}$ in the temperature range of 25 to $140{ }^{\circ} \mathrm{C}$. The samples were heated at a rate of $3{ }^{\circ} \mathrm{C} / \mathrm{min}$ in each experiment.

The impact specimens were broken in liquid nitrogen and coated with gold. The morphology of the cross sections was characterized with scanning electron microcopy (SEM) on a FEI Quanta 200 apparatus. The acceleration voltage was $20.0 \mathrm{kV}$.

\section{RESULTS AND DISCUSSION}

\section{Fractionation of Soda Lignin}

SL was divided into two fractions based on the difference in dissolution behaviors of lignin with different molecular weights in solvents with various polarity (Morck et al. 1986). The fractionation yield, molecular weight distributions, and phenolic hydroxyl group contents of two lignin fractions, as well as those in total SL, are given in Table 2. LA exhibited relatively low molecular weight and narrow distribution, while LB exhibited higher molecular weight and wider distribution than the un-fractionated lignin did. The content of phenolic hydroxyls in LB was lower than that of LA. Generally, the high molecular weight fraction of lignin showed higher crosslinking degree and steric hindrance than low-molecular-weight fraction does, while the former was less reactive. Therefore, LA, the low molecular weight lignin fraction, was used to synthesize lignin amine in order to improve the reaction efficiency in this investigation.

Table 2. Characteristics of Soda Lignin and its Fractions

\begin{tabular}{cccc}
\hline Sample & SL & LA & LB \\
\hline Weight ratio (\%) & - & 38.6 & 51.9 \\
$\overline{M_{w}}$ & 9180 & 4510 & 25420 \\
$\overline{M_{n}}$ & 4680 & 2970 & 7320 \\
Polydispersity & 1.96 & 1.52 & 3.47 \\
$\mathrm{OH}_{\text {phen }}(\mathrm{mmol} / \mathrm{g})$ & 3.52 & 3.65 & 3.01 \\
$T_{g}\left({ }^{\circ} \mathrm{C}\right)$ & 152.9 & 131.8 & 185.6 \\
\hline
\end{tabular}

Yue et al. (2011). "PVC/wood bonding with lignin amine," BioResources 6(2), 2022-2034. 2025 


\section{Synthesis and Analysis of Lignin Amine}

The lignin amine was synthesized as shown in Fig. 1. The solubility of lignin amine in neutral or acidic aqueous solution was improved in comparison with that of unreacted lignin. The change in solubility can be attributed to the cationic characteristic of lignin amine caused by the introduction of amine units (Hoftiezer et al. 1984; McKague 1974).

Figure 2 shows the FT-IR spectra of lignin and lignin amine. The absorption at $2940 \mathrm{~cm}^{-1}$, which represents the C-H stretching vibration in $-\mathrm{CH}_{2}-$, increases in the FT-IR spectra of lignin amine in comparison with that of un-reacted lignin. The band at 817 $\mathrm{cm}^{-1}$ is due to the stretching vibrations of $\mathrm{C}-\mathrm{H}$ for $\mathrm{C}_{2}, \mathrm{C}_{5}$ and $\mathrm{C}_{6}$ in the aromatic ring. This absorption decreases in the FT-IR spectra of lignin amine in comparison with that of unreacted lignin. The changes of the absorption at $2940 \mathrm{~cm}^{-1}$ and $817 \mathrm{~cm}^{-1}$ show that the $-\mathrm{H}$ of $\mathrm{C}_{5}$ in the aromatic ring was substituted by $-\mathrm{CH}_{2}$ - group. The bands at $1084 \mathrm{~cm}^{-1}$ and $1216 \mathrm{~cm}^{-1}$ in the spectra can be assigned to the stretching vibration of C-N bonds. These two absorptions increase in the spectra of lignin amine, indicating that amino groups were introduced into the lignin marcomolecules.

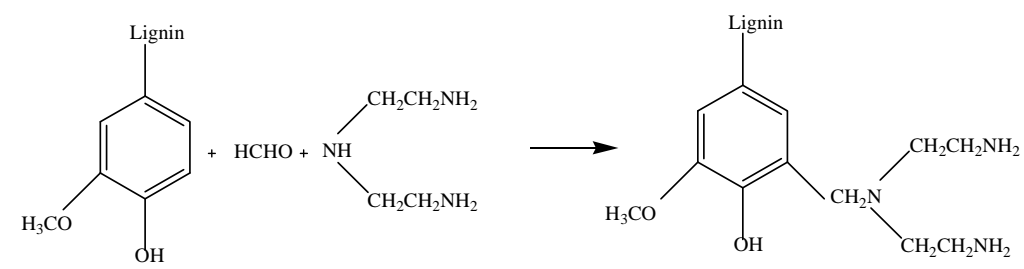

Fig. 1. Synthesis pathway of lignin amine by Mannich reaction

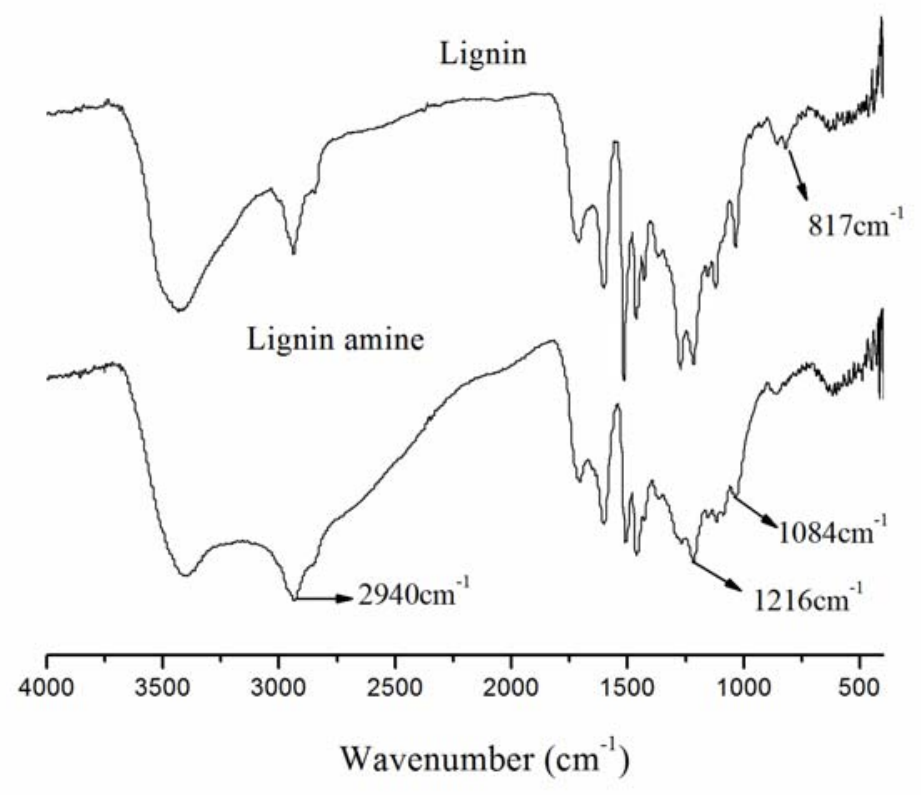

Fig. 2. FT-IR spectra of lignin and lignin amine 
The elemental composition of lignin and lignin amine are shown in Table 3. The nitrogen content increased to $8.18 \%$ in lignin amine from $0.89 \%$ in un-reacted lignin. The data also indicate that the amine units were introduced into the lignin macromolecules.

Table 3. Elemental Compositions of Lignin and Lignin Amine

\begin{tabular}{ccccc}
\hline Sample & $\mathrm{C}(\%)$ & $\mathrm{H}(\%)$ & $\mathrm{O}(\%)$ & $\mathrm{N}(\%)$ \\
\hline Lignin & 60.45 & 7.36 & 30.67 & 0.89 \\
Lignin amine & 55.33 & 9.38 & 26.11 & 8.18 \\
\hline
\end{tabular}

\section{Mechanical Performances of PVC/Wood-Flour Composites}

The lignin amine and aminosilane were used in the surface treatment of wood flour. The lignin amine treatment significantly improved the mechanical performances of PVC/wood-flour composites. An experiment was used to identify the most suitable loading of lignin amine with the same wood flour loading. Figure 3 plots the tensile and impact strengths of PVC-30LWF as a function of lignin amine loading.

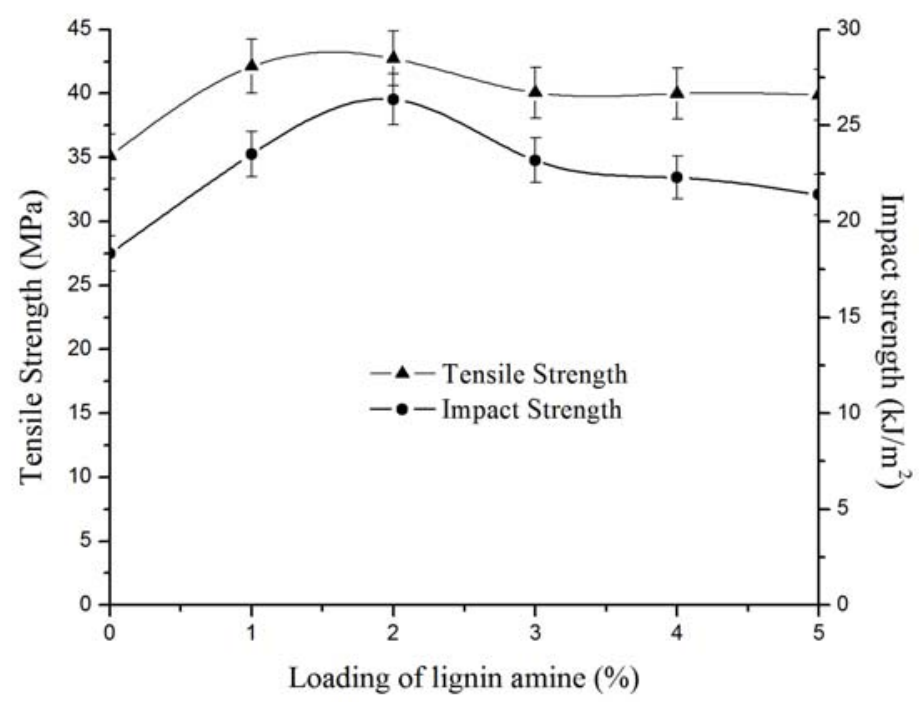

Fig. 3. Effect of lignin amine loading on the tensile and impact strengths of PVC/wood-flour composites (The loading of wood flour was 30phr.)

The tensile strength of the composites increased with the initial increase in lignin amine loading, with the maximum value being achieved when the loading of lignin amine was $2 \%$. The tensile strength of composite then declined when the loading of lignin amine exceeded $2 \%$. A similar trend for the impact strength was observed. In comparison with PVC-30UWF, the tensile and impact strengths of PVC-30LWF (2wt\% lignin amine treated) increased by $21.0 \%$ and $43.9 \%$, respectively. These data demonstrate that excessive lignin amine does not favor the improvement of mechanical performances. It has been argued that, as the interface becomes saturated, the compatibilizer gets trapped in one of the phases and the system behaves like a ternary blend (Sundararaj and Macosko 1995). 
When wood flour was treated by excessive lignin amine, a multi-molecular layer was formed on the surface of wood flour. Based on this point of view, the variations of tensile and impact strengths of composites that treated by lignin amine or aminosilane are reasonable.

Figure 4 plots the tensile and impact strengths of PVC-30KWF as a function of aminosilane loading. Similar trends were observed when wood flour was treated by aminosilane. The PVC-30KWF (1wt\% aminosilane treated) showed the highest tensile and impact strengths.

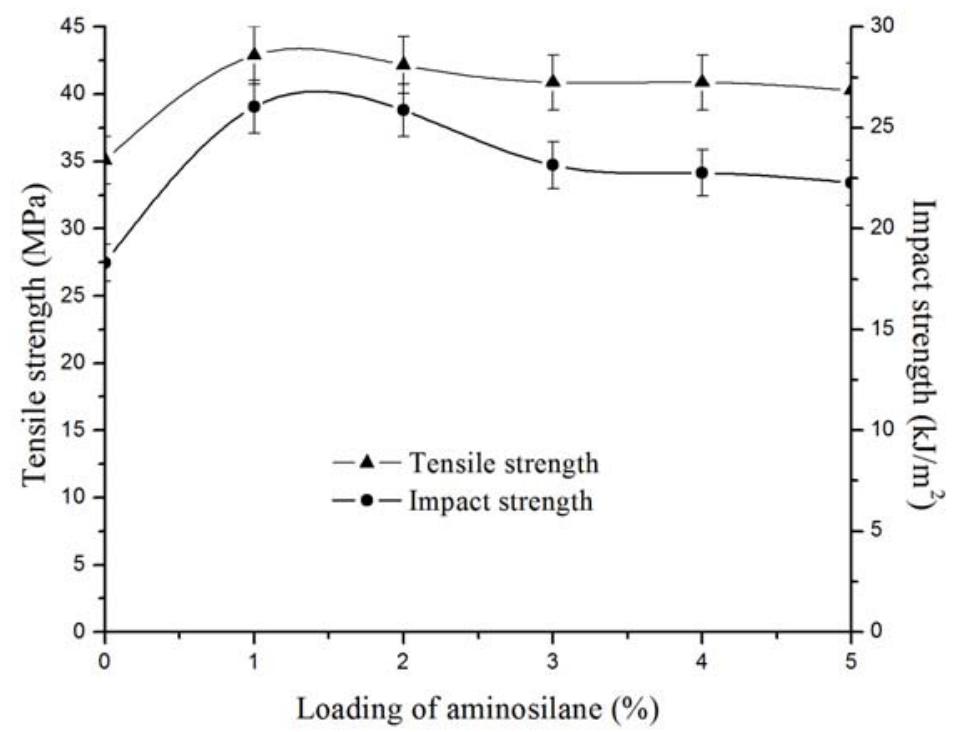

Fig. 4. Effect of aminosilane loading on the tensile and impact strengths of PVC/wood-flour composites (The loading of wood flour was 30phr.)

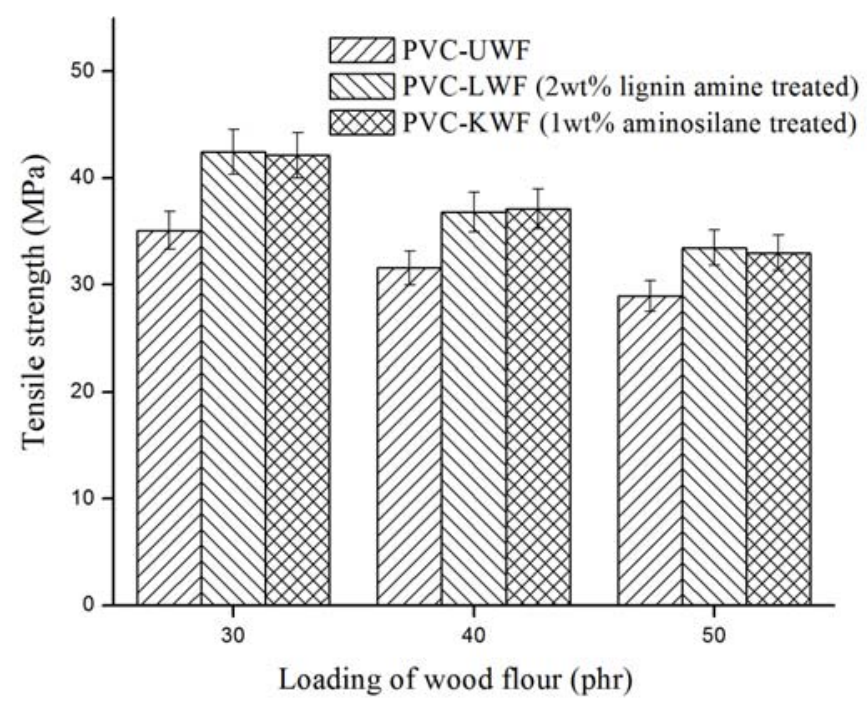

Fig. 5. Tensile strength of PVC/wood-flour composites with different treatments 


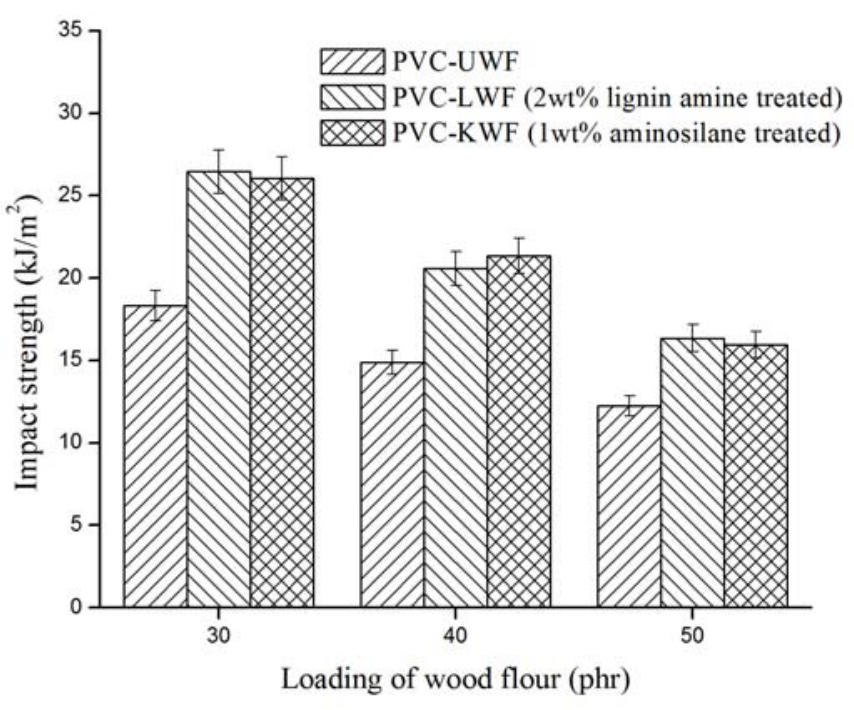

Fig. 6. Impact strength of PVC/wood-flour composites with different treatments

Based on the optimum loading of lignin amine and aminosilane, PVC-LWF (2wt\% lignin amine treated) and PVC-KWF (1wt\% aminosilane treated) were selected to compare the coupling effect of lignin amine and aminosilane in their respective composites. Figures 5 and 6 show the tensile and impact strengths of composites that were prepared from varied amount of wood flour with different surface treatment, respectively. In comparison with the untreated samples, the composites containing 30, 40, and 50phr wood flour treated with lignin amine and aminosilane all showed improved tensile and impact strengths. Furthermore, the lignin amine treatment and aminosilane treatment provided almost equivalent improvement in mechanical performances of composites. It was reported that the acid-base interactions between aminosilane treated fibers and PVC matrix appeared to be a great factor in the improvement in the strength of the composite (Matuana et al. 1998a,b). Thus, the coupling effect of lignin amine on the composite may be attributed to the similar structural characteristic between lignin amine and aminosilane. When the lignin amine was incorporated into the formulation, hydrogen bonds may have been formed between the hydroxyl groups of the wood flour and lignin amine. The wood surface that was treated by lignin amine exhibited a more basic characteristic. During the processing procedure, strong interfacial adhesion between the chlorine-containing PVC and amino groups on the surface of wood flour, which resulted in significant improvement in the mechanical performances of the composites, was established (Matuana et al. 1998a,b; Shah et al. 2005). From the view of acid-base interaction, aminosilane, chitosan and lignin amine exhibited a similar coupling mechanism due to its having the same functional groups.

\section{Water Absorption}

The water absoption of PVC-50UWF, PVC-50LWF (2wt\% lignin amine treated) and PVC-50KWF (1wt\% aminosilane treated) after 10days immersion were evaluated. Figure 7 shows the water absorption curves of PVC/wood-flour composites. 


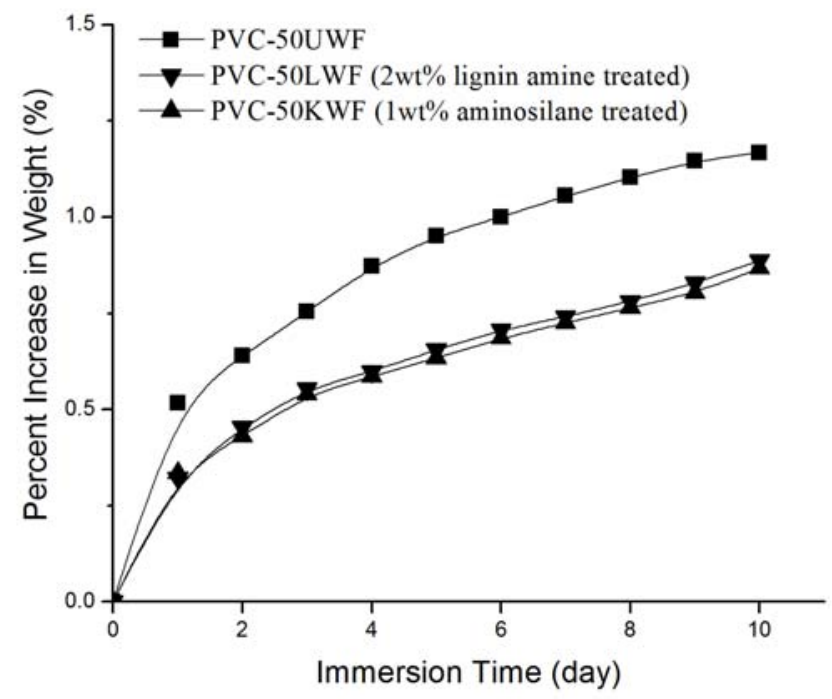

Fig. 7. Effect of surface treatments on the water absorption of PVC/wood-flour composites

Although the water absorption of composites didn't reach steady state, it was found that the PVC-50UWF showed higher water absorption than any other samples. Lignin amine treatment and aminosilane treatment both lowered the water absorption of composites. It was reported that coupling agent had an ability to interact with hydroxyl groups of wood flour, thus blocking the latter from hydrogen bonding with water (Abu Bakar et al. 2010).

The decline in water absorption demonstrates that the hydroxyls in the surface of wood flour were covered as a result of treatment and the interfacial adhesion between wood flour and PVC matrix was improved. Furthermore, the water absorption curves of PVC-50LWF (2wt\% lignin amine treated) and PVC-50KWF (1wt\% aminosilane treated) are almost overlapped. This may be attributed to the similar coupling mechanism of lignin amine and aminosilane.

\section{Dynamic Mechanical Analysis}

Based on the optimum mechanical performances, PVC-30LWF (2wt\% lignin amine treated) and PVC-30KWF (1wt $\%$ aminosilane treated) were selected for DMA study. The DMA curves of rigid PVC and the composites are shown in Fig. 8.

It was found that the storage modulus $\left(E^{\prime}\right)$ of the composite was slightly increased by the incorporation of wood flour. This result indicates that the wood flour acts as a reinforcing agent for the PVC matrix, thereby increasing the stiffness of the matrix. The composites prepared with treated wood flour showed a much greater increase in $E$ ' than the untreated one. The large increase in $E$ ' is attributed to an improved adhesion between wood-flour and matrix. This result is well consistent with those where chitosan was used as coupling agents for preparing PVC/wood-flour composites (Shah et al. 2005). 


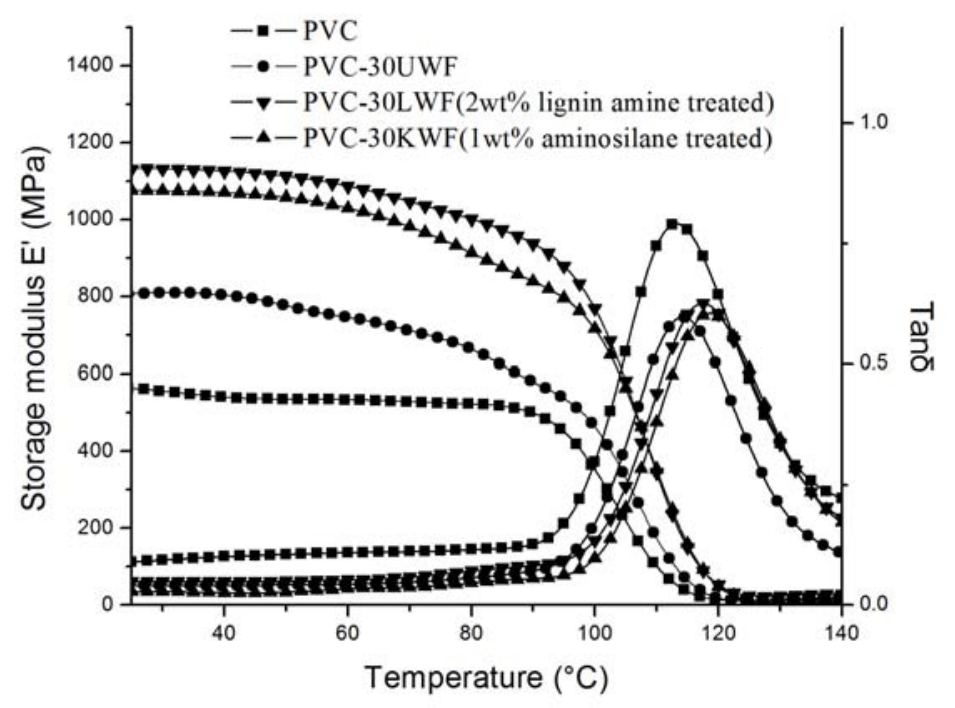

Fig. 8. DMA curves of rigid PVC and PVC/wood-flour composites

The mechanical damping parameter $(\tan \delta$ ) reflects the mobility of molecular segments. It was noticed from Fig. 8 that the peak value of $\tan \delta$ was reduced when wood flour was added. The glass transition temperature $\left(T_{g}\right)$ was found to increase slightly to $114.3^{\circ} \mathrm{C}$ from the original data, $112.5{ }^{\circ} \mathrm{C}$, by the incorporation of wood flour. This clearly implies that the molecular mobility of the PVC segments during the glass transition was slightly constrained by wood flour. Similar results have been reported (Saini et al. 2010). When the wood flour was treated with lignin amine or aminosilane, the $T_{g}$ of the composite was increased to $116.5{ }^{\circ} \mathrm{C}$ and $117.5{ }^{\circ} \mathrm{C}$, respectively. This indicates that the constraint effect of wood flour on the PVC matrix was strengthened by the addition of lignin amine or aminosilane. This may be attributed to the acid-base interaction on the interface between wood flour and PVC matrix.

\section{Morphology of PVC/Wood-Flour Composites}

The SEM images of the cross sections of rigid PVC and PVC/wood-flour composites are shown in Fig. 9. Smooth cross sections were observed in the SEM images of rigid PVC (Fig. 9a). Irregular pores, however, were observed in the composite prepared from untreated wood flour, as shown in Fig. 9b. This may be attributed to the pulling out of wood flour during free tearing, demonstrating the poor interfacial adhesion between wood flour and the PVC matrix. Figure 9c shows the cross section of composite prepared from wood flour which was treated by lignin amine. The amount of pores caused by the removal of wood flour was decreased. Wood fibers were embedded in the PVC matrix and dispersed rather uniformly, illustrating the adhesion between the two components. It can be inferred that wood flour treated by lignin amine achieved better compatibility with PVC matrix than untreated wood flour. As shown in Fig. 9d, the dispersion status of wood flour that was treated by aminosilane in PVC matrix was similar to that of wood flour treated by lignin amine. The information obtained from SEM images is consistent with the results of mechanical properties. 

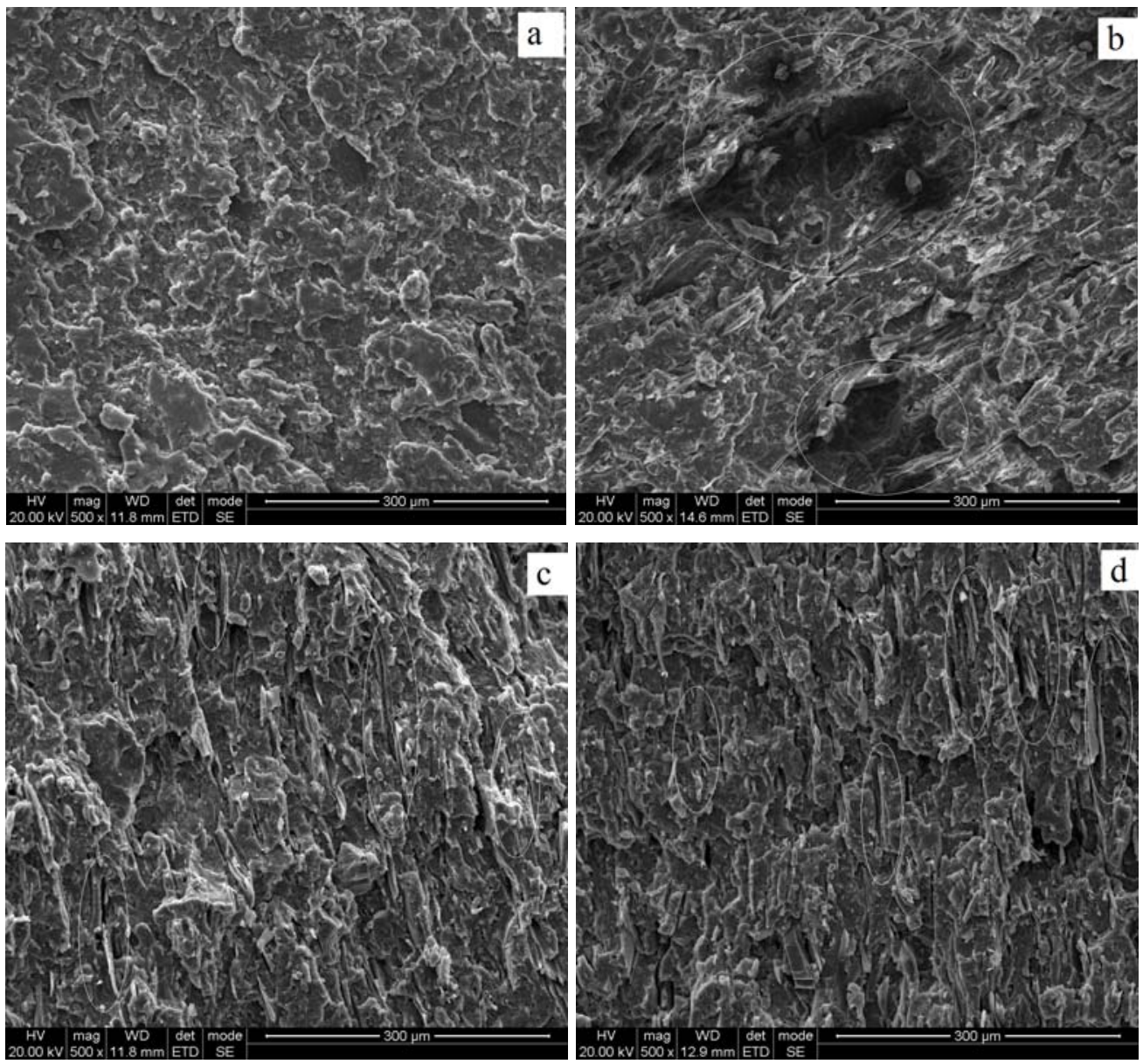

Fig. 9. SEM images of PVC/wood-flour composites: (a) Rigid PVC; (b) PVC-30UWF; (c) PVC30LWF (2Wt\% lignin amine treated); (d) PVC-30KWF (1wt\% aminosilane treated)

\section{CONCLUSIONS}

Lignin amine was synthesized from low molecular weight fraction of lignin via a Mannich reaction. The lignin amine favored improved mechanical performances of PVC/wood-flour composites. The lignin amine treatment provided almost equivalent improvement in mechanical performances of composites as aminosilane treatment does. The tensile and impact strengths of the composite achieved the maximum value when the wood flour was treated by $2 \mathrm{wt} \%$ lignin amine. Furthermore, Lignin amine treatment could also significantly reduce the water absorption of composites. The composite prepared by wood flour with lignin amine treatment showed higher $E$ ' than that of untreated samples. The wood flour treated with lignin amine showed improved interfacial bonding with PVC matrix in comparison with untreated wood flour. 


\section{ACKNOWLEDGMENTS}

The authors appreciate Hi-Tech Research and Development Program of China (Contract grant number: 2007AA100704) and the National Basic Research Program of China (Contract grant number: 2010BC732206) for financial support.

\section{REFERENCES CITED}

Abu Bakar, A., Hassan, A., and Yusof, A. F. M. (2010). “Mechanical properties of silane and zirconate coupling agent-treated Oil palm Eempty fruit bunch fiber-filled acrylicimpact modified Poly (vinyl chloride) composites," Polym-Plast Technol. 49(15), 1563-1570.

Bengtsson, M., and Oksman, K. (2006). "The use of silane technology in crosslinking polyethylene/wood flour composites,” Compos Part A-Appl S. 37(5), 752-765.

Bledzki, A. K., Reihmane, S., and Gassan, J. (1998). "Thermoplastics reinforced with wood fillers: A literature review,” Polym-Plast Technol. 37(4), 451-468.

Cetin, N. S., and Ozmen, N. (2002). "Use of organosolv lignin in phenol-formaldehyde resins for particleboard production. I. Organosolv lignin modified resins,” Int. J. Adhes. Adhes. 22(6), 477-480.

Dilling, P., and Samaranayake, G. S. (1999). "Mixtures of amine modified lignin with sulfonated lignin for disperse dye,” US Patent 5,989,299.

El-Mansouri, N. E., and Salvadó, J. (2007). “Analytical methods for determining functional groups in various technical lignins,” Ind. Crop. Prod. 26(2), 116-124.

Garcia-Hernandez, E., Licea-Claverie, A., Zizumbo, A., Alvarez-Castillo, A., and Herrera-Franco, P. J. (2004). "Improvement of the interfacial compatibility between sugar cane bagasse fibers and polystyrene for composites,” Polym Compos. 25(2), 134-145.

Georgopoulos, S. T., Tarantili, P. A., Avgerinos, E., Andreopoulos, A. G., and Koukios, E. G. (2005). "Thermoplastic polymers reinforced with fibrous agricultural residues," Polym Degrad Stabil. 90(2), 303-312.

Hoftiezer H. W., Watts D. J., and Takahashi A. (1984). "Cationic reaction product of kraft lignin with aldehyde and polyamine,” US Patent 4,455,257.

Ichazo, M. N., Albano, C., Gonzalez, J., Perera, R., and Candal, M. V. (2001). "Polypropylene/wood flour composites: Treatments and properties," Compos Struct. 54(2-3), 207-214.

Jiang, H. H., and Kamdem, D. P. (2004). “Development of poly (vinyl chloride)/wood composites - A literature review,” J. Vinyl. Addit. Techn. 10(2), 59-69.

Kelley, S. S., Ward, T. C., and Glasser, W. G. (1990). "Multiphase materials with lignin. VIII. Interpenetrating polymer networks from polyurethanes and poly methyl methacrylate,” J. Appl. Polym. Sci. 41(11-12), 2813-2828.

Lin S. Y. (1985). "Reaction product of lignosulfonate and unsaturated fatty amine,” US Patent 4,562,236. 
Lu, J. Z., Wu, Q. L., and Mcnabb, H. S. (2000). “Chemical coupling in wood fiber and polymer composites: A review of coupling agents and treatments,” Wood Fiber Sci. 32(1), 88-104.

Matuana, L. M., Balatinecz, J. J., and Park, C. B. (1998a). "Effect of surface properties on the adhesion between PVC and wood veneer laminates,” Polym. Eng. Sci. 38(5), 765-773.

Matuana, L. M., Woodhams, R. T., Balatinecz, J. J., and Park, C. B. (1998b). “Influence of interfacial interactions on the properties of PVC/cellulosic fiber composites," Polym Compos. 19(4), 446-455.

McKague, A. B. (1974). "Flocculating agents derived from kraft lignin,” J. Appl. Chem. Biotechnol. 24(10), 607-615.

Morck, R., Yoshida, H., and Kringstad, K. P. (1986). "Fractionation of kraft lignin by successive extraction with organic solvents I. Functional group, ${ }^{13} \mathrm{C}-\mathrm{NMR}$-spectra and molecular weight distributions," Holzforschung. 40(1), 51-60.

Saini, G., Bhardwaj, R., Choudhary, V., and Narula, A. K. (2010). "Poly (vinyl chloride)Acacia bark flour composite: Effect of particle size and filler content on mechanical, thermal, and morphological characteristics,” J. Appl. Polym. Sci. 117(3), 1309-1318.

Shah, B. L., Matuana, L. M., and Heiden, P. A. (2005). "Novel coupling agents for PVC/wood-flour composites,” J. Vinyl. Addit. Techn. 11(4), 160-165.

Sun, G., Sun, H. G., Liu Y., Zhao, B. Y., Zhu, N., and Hu, K. A. (2007). “Comparative study on the curing kinetics and mechanism of a lignin-based-epoxy/anhydride resin system," Polymer. 48(1), 330-337.

Sundararaj, U., and Macosko, C. W. (1995). "Drop breakup and coalescence in polymer blends: The effects of concentration and compatibilization,” Marcomolecules. 28(8), 2647-2657.

Article submitted: March 18, 2011; Peer review completed: April 17, 2011; Revised version received and accepted: April 19, 2011; Published: April 21, 2011. 